\title{
How to deal with non-linear pathways towards energy futures
}

\section{Concept and application of the cross-impact balance analysis}

\author{
Stefan Vögele, Institute of Energy and Climate Research - Systems Analysis and Technology Evaluation (IEK-STE), \\ Forschungszentrum Jülich, 52425 Jülich (s.voegele@fz-juelich.de), (1) orcid.org/0000-0002-5804-0203 \\ Witold-Roger Poganietz, Institute for Technology Assessment and Systems Analysis (ITAS), Karlsruhe Institute of Technology (KIT) \\ (poganietz@kit.edu), (1) orcid.org/0000-0002-5839-1206 \\ Philip Mayer, Chair of Economics, TU Bergakademie Freiberg (philip.mayer@vwl.tu-freiberg.de), (1) orcid.org/0000-0002-8221-6002
}

Energy scenarios currently in use for policy advice are based on a number of simplifying assumptions. This includes, in particular, the linear extrapolation of trends. However, this approach ignores the fact that central variables were highly dynamic in the past. For an assessment of energy futures and the specification of measures, novel approaches are necessary which can implement non-linear trends. In this paper, we show how cross-impact balance ( $\mathrm{CIB}$ ) analysis can be applied to map dynamic trends. Using a small CIB model, we highlight the need for novel approaches in the creation and evaluation of energy futures and the possible contribution of CIB analysis.

\section{Wie lassen sich nichtlineare Entwicklungspfade von Energie- zukünften berücksichtigen? \\ Konzept und Anwendung der Cross-Impact-Analyse}

Den Energieszenarien, die derzeit zur Politikberatung genutzt werden, liegen eine Vielzahl vereinfachender Annahmen zugrunde. Hierzu gehört insbesondere die Fortschreibung von Rahmendaten mittels linearer Trendextrapolation. Ignoriert wird dabei, dass zentrale Größen in der Vergangenheit eine hohe Dynamik aufwiesen. Um Energiezukünfte erstellen, bewerten bzw. Vorschläge zu deren Ausgestaltung angemessen formulieren zu können, bedarf es neuer innovativer Ansätze, in denen nichtlineare Entwicklungen berücksichtigt werden können. In diesem Artikel zeigen wir, wie die Cross-Impact-Balance-Analyse (CIB) zur Abbildung von dynamischen Entwicklungen eingesetzt werden kann. Anhand eines kleinen CIB-Modells verdeutlichen wir die Notwendigkeit für Weiterentwicklungen im Bereich der Erstellung und Bewertung von Energiezukünften und den Beitrag, den die CIB-Analyse dazu leisten kann.

Keywords: energy scenarios, dynamics, cross-impact balance analysis

This is an article distributed under the terms of the Creative Commons Attribution License CCBY 4.0 (https://creativecommons.org/licenses/by/4.0/)

https://doi.org/10.14512/tatup.28.3.20

Submitted: 02.07.2019. Peer reviewed. Accepted: 23.10.2019

\section{Introduction}

Socio-economic systems, like the energy system, are evolutionary systems. Path dependencies and persistence resulting for instance from long lifetimes of technological infrastructures (i. e., power plants) and incumbent energy companies with low interest in radical innovations stabilize the dynamics of the systems (Patel and Pavitt 1997; Safarzynska and van den Bergh 2010). As long as the dynamics of the system do not change, possible futures of the corresponding system can be assessed more or less easily. But, the dynamics of these systems do not only depend on technical innovations (Grubler and Wilson 2013) but also on changes in institutions, socio-economic structures, and policies on local, national, and global level, within and outside the system (Nelson and Winter 2002; Nelson and Winter 1982; Fagerberg 2003; Metcalfe 1994; Witt 2008). Examples for such occurrences are the liberalization of energy markets, or long-run changes in the attitudes of the government and the public towards nuclear power plants in Germany, Sweden, Switzerland and Belgium, which were caused in particular by changes in the composition of the government (World Nuclear Association 2019). Also ups and downs of climate change policies (Zhang et al. 2017), financial crises on an international level as well as arising conflicts between countries (e.g., USA and China/USA and Iraq) can play an important role. Thus, a broad range of authors - including Schumpeter (1943), Veblen (1898), Nelson and Winter (1982) and Faber and Proops (1993) - highlight the need for a closer consideration of non-linear dynamics. Disruptions and discontinuities have been analyzed e. g. by Ayres (2000), Burt (2007), Grossmann (2007), Lempert and Collins (2007) as well as van Notten et al. (2005). However, for reason of simplification, the construction of energy scenarios still relies on the assumption of stable, mostly linear, trends for the development of key factors (like oil prices, or GDP), instead of complex development trajectories. Information on trends is derived from historical data or expert appraisal (Kosow and Gaßner 2008; Bauer et al. 2017). 
Examples for assumed trends of key factors that influence future energy supply and demand are presented in Fig. 1. At the top of the figure, the trends for the development of oil and gas prices used in the newest energy outlook of IEA (2018) are presented. Comparing historical and projected prices, doubts about the reliability of the assumed trajectories (and hence on the resulting scenarios) could arise. Similar concerns could be voiced with regard to the scenarios published by the EU (Capros et al. 2016; EIA 2019).

Thus, working with trends carried out by either extrapolation or expert assessments has some shortcomings:

- Without critical reflections on the persistence of trends in the long term, the use of extrapolated trends may result in a misjudgment of possible dynamics.

- Although the link between key factors and the dynamics within a system are generally recognized, a closer investigation is often not carried out, due to missing expertise or time constraints. Hence, cyclical trends like business cycles or possible breaks in the development of key figures are ignored.

Fluctuating prices for energy carries, business cycles and modifications in the prioritization of policies are examples for challenges that scenarios are faced with. Technological leaps (e. g., digitalization), effects resulting from changes in the zeitgeist (e. g., Fridays for Future movement), modifications in the priority setting of policies as well as international crises (e. g., trade war between countries) are other examples for factors that could disrupt trends.

Studies focusing on climate change or ecosystem analysis highlight "critical thresholds", "critical levels" and "critical loads" as factors behind the occurrence of nonlinearities (IPCC 2001; IPCC 2018). Like ecosystems, thresholds and critical levels are also important in socio-economic systems. For example, the long-run success of development policies crucially depends on passing critical national income thresholds (Azariadis and Drazen 1990). Other examples are social and cultural obstacles that can limit the use of specific technologies as soon as the corresponding technology reaches a "critical" market share. As examples for barriers that limit diffusion of technology beyond a "critical" market share, IPCC listed social norms, individual habits, attitudes, values, and vested interests (IPCC 2001; IPCC 2011).

In principle, thresholds and resulting nonlinearities can impact the efficiency and effectiveness of policy measures as well as the cost of adaptation and mitigation. An appropriate assessment of possible courses of action and their timing requires structured approaches that can deal with thresholds, cycles and the resulting dynamics.

In the following, we present an approach for integrating thresholds and cycles, which allows for the construction of nonlinear storylines. Hence, the presented work contributes to an important strand of scenario development and adds a relevant aspect to the discussion about energy futures (or transformation processes).
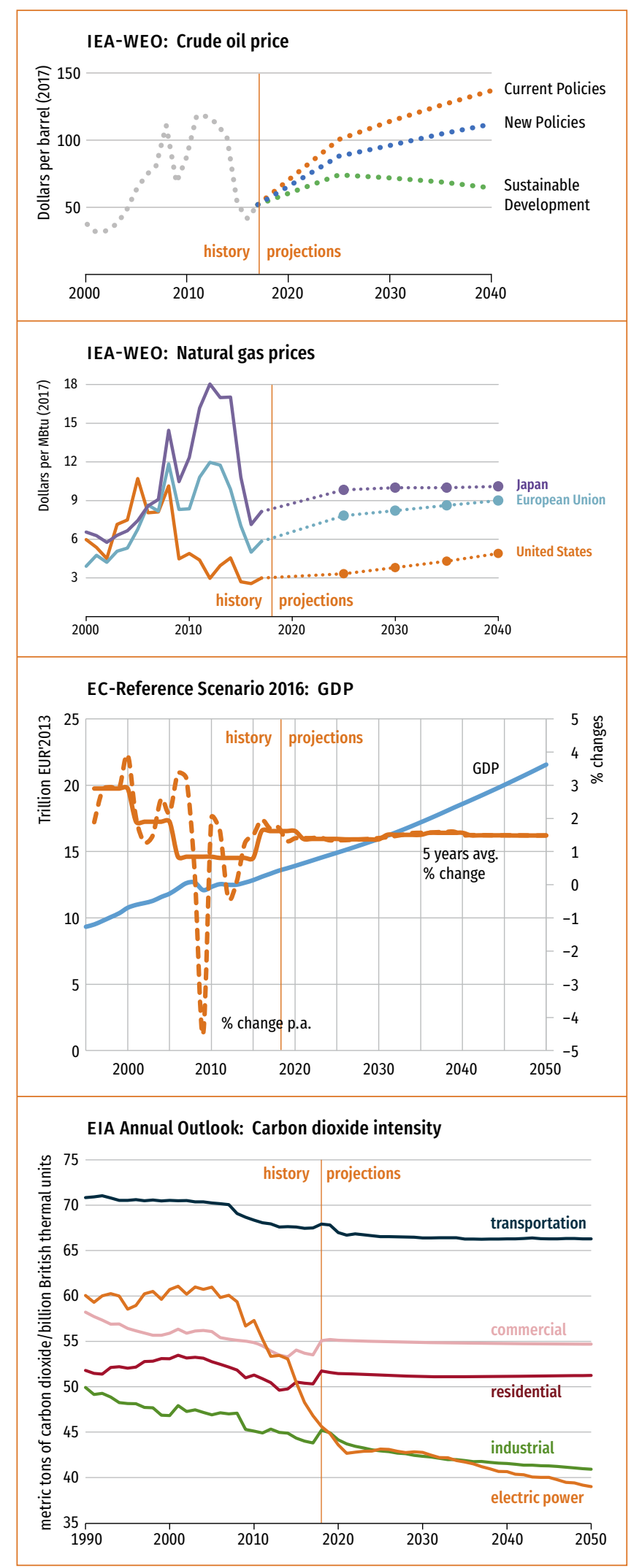

Fig 1: Examples for assumptions on key factors used for the generation of energy scenarios. 


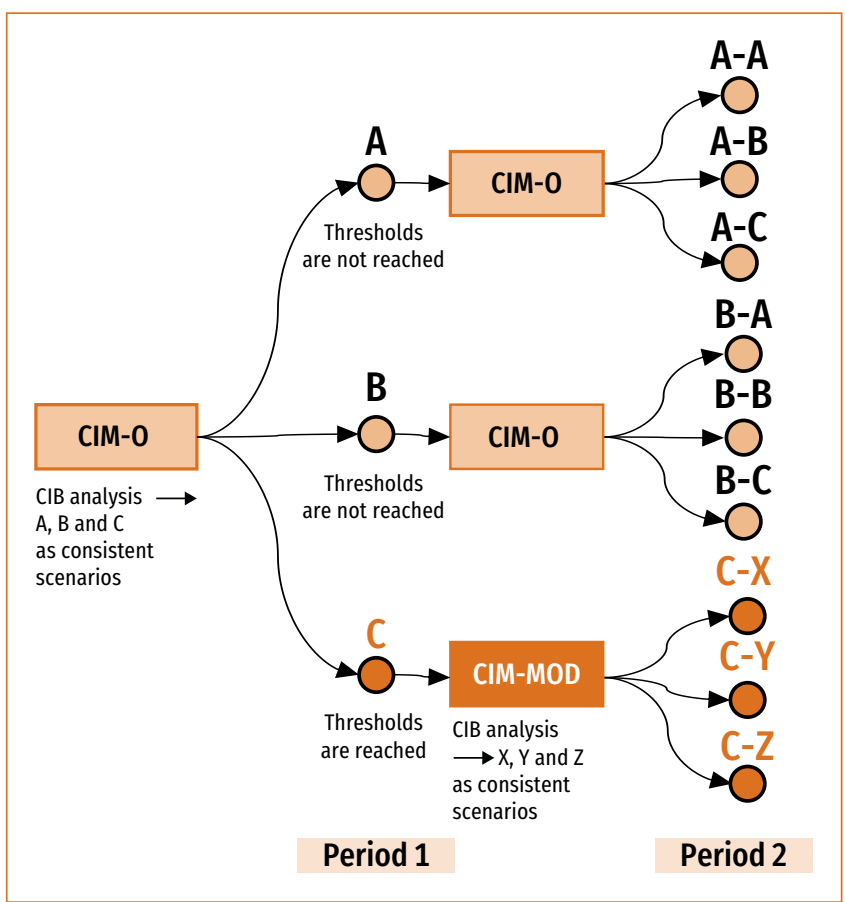

Fig.2: Identification of Transformation Pathways.

Source: Authors' own compilation

\section{Advanced energy modelling - considering non-linearities}

Generally, scenarios are constructed on the base of today's knowledge and expectation about the future (Kosow and Gaßner 2008). Using today's shape of the system under review as a starting point, relevant variables or parameters are extrapolated into the future. This exercise is generally done, without changing the structural relationships within a system.

Historical evidence shows, however, that the structural relationships of a system change over time. Agrarian or emerging societies are functioning differently than industrial or post-industrial ones. This is even true without a complete systems' change (Mathijs and Swinnen 2001; de Bruyn et al. 1998).

Furthermore, historical evidence shows the existence of thresholds, which are connected to a shift of behaviour of societies. If, for example, a society is achieving a specific welfare level the production structure, as well as the demand structure is shifting from more basic mostly energy-intensive products to services and lighter industries (IEA 2016), leading to a decoupling of energy demand from income development. Higher income levels allow for more energy-efficient technologies whereas in a society with low levels of average income changes in income will be used to buy for example electric appliances or cars with lower energy standard (de Bruyn et al. 1998; IEA 2018).

The Cross-Impact-Balance (CIB) approach allows for specifying consistent socio-economic storylines (Weimer-Jehle 2006;
Weimer-Jehle et al. 2016; Schweizer and Kriegler 2012). Similar approaches have been developed and applied in the field of environmental scenario analysis. Examples are the "Story and Simulation" approach (Alcamo and Henrichs 2008), "integrated scenarios" (Döll and Krol 2002), "narratives and numbers" (Kemp-Benedict 2004), and the "hybrid scenarios" approach (Winterscheid 2008).

The core idea of the CIB approach is to find a set of quantitative and qualitative factors, so-called descriptors, and possible (future) states for each descriptor, which could characterize the system under review. Formally speaking the descriptors and states are merged into a cross-impact matrix (CIM), which reveals the interrelationship between the different descriptor-states. By combining possible descriptor-states' arrangements to consistent sets, one or more possible futures of the system can be identified. However, possible changes of the interdependency between descriptor-states are usually not recognized, implying a linear development of the socio-economic system.

In principle, CIB allows for modelling and analyzing thresholds and cycles. A way to overcome the linearity of the CIB approach (i. e., implementing cycles and thresholds) is using descriptor states describing developments (e.g., "increase of GDP for 5 years, followed by a drop in the next 5 years") or introducing sub-periods and crucial descriptors (see Vögele et al. 2018a for more information on advantages and disadvantages of the different approaches). Those descriptors can either trigger a change in interdependencies within the CIM as soon as a certain threshold is reached, or they exhibit cyclic behaviour (i. e., their state in the current sub-period is affected by their state in the previous sub-period).

In the introduced method, the considered period is divided into several sub-periods. Starting with the first sub-period a CIM is constructed and several scenarios are identified, each describing a possible future. These possible futures are analyzed with respect to specific crucial descriptors. In the example depicted in Fig. 2, the CIB analysis reveals a set of three consistent fu-

\section{Historical evidence shows the existence of thresholds, which are connected to a shift of behaviour of societies.}

tures A, B and C for the first sub-period. As soon as a pre-defined threshold is reached, a modified CIM is created, resulting in a new scenario space.

The modified matrix, labelled CIM-MOD in Fig. 2, is used for calculating the next set of scenarios for the description of the subsequent periods following future $\mathrm{C}$. This exercise is repeated until consistent scenarios are generated for all sub-periods. Fol- 


\begin{tabular}{|c|c|c|c|c|c|c|}
\hline Descriptors & Category & $\begin{array}{l}\text { Possible variations } \\
1\end{array}$ & 2 & 3 & 4 & 5 \\
\hline D1: Global economic cohesion & Static & Protectionism & Open economies & $\begin{array}{l}\text { Bilateral trade } \\
\text { agreements }\end{array}$ & & \\
\hline $\begin{array}{l}\text { D2: Trade of energy } \\
\text { commodities }\end{array}$ & Static & Trade restrictions & $\begin{array}{l}\text { No trade } \\
\text { restrictions }\end{array}$ & & & \\
\hline D3: Energy commodity prices & Static & Increase & Constant & Decrease & & \\
\hline D4: GDP Growth & Threshold/Cyclic & $\begin{array}{l}\text { Very small } \\
\text { increase }\end{array}$ & Small increase & Moderate increase & High increase & Very high increase \\
\hline D5: Climate policy & Static & Unambitious & Moderate & Ambitious & & \\
\hline D6: Energy consumption & Threshold & Slight increase & Moderate increase & Strong increase & & \\
\hline
\end{tabular}

Tab.1: Specification of descriptors and their variations.

Source: Authors' own compilation

lowing this approach, a set of consistent, plausible, and non-linear transformation pathways can be identified.

In order to illustrate the modelling of nonlinearity, we apply a CIB model with a set of six descriptors (Tab. 1). We differentiate between three types of descriptors. Static descriptors do not actively trigger non-linear developments. Thus, their mechanism resembles the original CIB method. Interdependencies for threshold descriptors change as soon as a certain limit value is reached. The state of cyclic descriptors in the current period is dependent on their state in the previous sub-period.

As an example for a threshold, we assume that in the beginning, energy consumption increases with economic growth. When the economic growth exceeds a defined level, energy con- sumption will be partially decoupled from the development of national income (e.g., via technologies with higher energy efficiency) (IEA 2016). As another source for nonlinearities, we consider business cycles: We assume that it is likely that a period of high economic growth is followed by a period with lower growth and vice versa.

We compare two illustrative scenarios: One scenario is developed using the original CIB analysis. A second scenario is constructed by employing the introduced methodology of dynamic pathways. The first scenario, which is referred to as "Joint forces" (JF), does not take into consideration dynamic interactions within the time horizon, and thus applies the original CIB method. The second scenario "Eleventh hour" (EH) em-

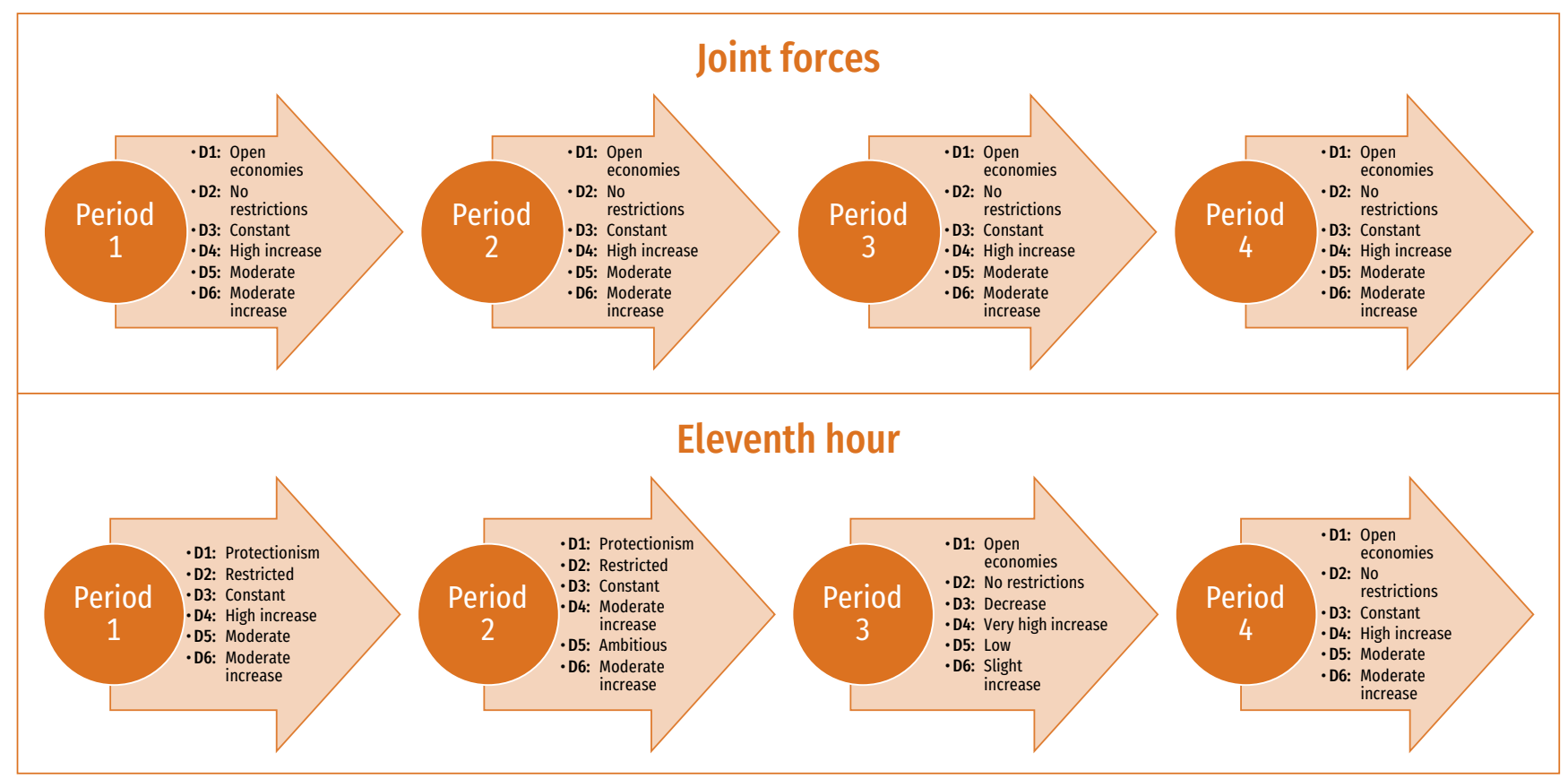

Fig. 3: Development of the descriptor sets in the storylines. 
ploys the introduced methodology of thresholds and cycles. In the last period, both EH and JF show the same set of descriptor states (Fig. 3).

Thus, a comparison of those two scenarios reveals the resulting differences of explicitly modelling dynamic pathways (EH) and assuming linear development trends (JF):

- Joined forces: In this scenario, the international community is characterized by harmony and a high level of cooperation on both economic and environmental issues. High economic growth facilitates investments in the exploration of fossil reservoirs, leading to constant prices for energy carriers. With resilient international trade agreements, economy-wide af- economic situation in the year 2050, the pathways leading to this point in time deviate strongly. JF assumes a linear trend of constant GDP growth, EH shows a fluctuating progression with periods of prosperity, economic booms and subdued growth. This affects the development of the power system via two interlinked channels: (i) due to the assumption of a direct influence of GDP trends on electricity consumption, diverging patterns of economic growth result in different amounts of power demand; (ii) the defined threshold that causes a shift of the interdependence between economic growth and electricity consumption is not triggered in JF. Hence, in this scenario power consumption exhibits a sharper rise, than in EH. Furthermore, the occurring shifts in the prioritization of climate policy are major drivers for

\section{Transformation pathways for energy systems have to be seen as evolutionary processes with nonlinear trends.}

fluence grows constantly. Although damages from climate change increase over time, negative effects are partly offset by strong economic growth. Consequently, climate change policy is only moderately emphasized within the international community. Nevertheless, in order to achieve the set climate goals, coal-fired power plants are slowly phased out, while the power markets transform towards a predominantly renewable energy system.

- Eleventh hour: The global economy thrives, which allows for new investments in the exploration of fossil storage sites. As a result, demand and supply of natural resources stay relatively balanced, leading to stable prices for energy commodities. Political tensions on the international level foster protectionist tendencies. With international collaboration continuously declining in the following years, and damages due to climate change, overall economic growth is constrained. As a result, national policy measures aiming to tackle the impacts of climatic change become more ambitious. However, due to the unfavorable economic setting, willingness to invest in new technological advancements is restrained. A shift in climate policy leads to a rapid phase-out of coal-fired power plants. In order to avoid the looming economic crises, the international community works towards building new institutions that regulate future cooperation. As a result, fuel prices drop. The elimination of trade barriers trigger a time of economic prosperity and wealth. Investments in new infrastructures and energy efficiency technologies lead to a less energy-intensive economy.

The descriptor sets depicted above are implemented into a European electricity market model (see Vögele et al. 2018b for more information on the model). The quantification of the two scenarios reveals distinctive development paths. While both scenarios share a common assumption on the general political and the layout of the future power market. The corresponding descriptor is implemented into the energy market modelling framework through carbon prices. The shifts in climate policy are accompanied by changing trends in energy carrier prices. Consequently, market conditions for power generators are subject to a state of flux, where the profitability of generation types can suddenly change between two periods. This means, that JF shows a steady transition of the electricity market towards a low-carbon system, where coal-fired power plants continuously lose profitability, as prices for $\mathrm{CO}_{2}$ emissions increase constantly. In contrast, EH displays a more abrupt fuel switch from coal to natural gas. Accordingly, the development of greenhouse gas emissions differs between the scenarios (Fig. 4).

As we can see, the sudden shift in climate policy in EH leads to a fast phase-out of coal-fired power plants in 2030. While gasfired power plants do not significantly contribute to the overall $\mathrm{CO}_{2}$ emissions in this scenario, the non-linear scenario shows a more dominant role for natural gas. In the last period, both scenarios display comparatively low emission levels for electricity generation. However, due to the lower electricity demand in $\mathrm{EH}$, overall emissions until 2050 are lower than in JF. Reasons for this development are: (i) the sudden shift in climate change policy leads to more abrupt phase-out of coal-fired power-plants; (ii) periods of lower economic growth lead to overall lower electricity demand; and (iii) the decoupling of electricity consumption and GDP growth additionally decreases electricity demand.

\section{Discussion and conclusion}

Taking developments of the past into consideration, it can be expected that transformation pathways for energy systems have to be seen as evolutionary processes with nonlinear trends. Windows of opportunities as well as times with restricted space for 
changes will characterize these processes. In order to ensure sustainable and efficient target attainment, the timing of the implementation of policy measures is of vital importance. However, only a part of future developments (including occurrence of thresholds or other kinds of disruptions in trends) is ascertainable in advance. Hence, there is a need for approaches that help to assess possible developments, that support the emergence of windows of opportunities, and that improve the perception and refine the senses for the uncertainty of the future. New systematic approaches that explore such dynamic features are vital in order to cre-

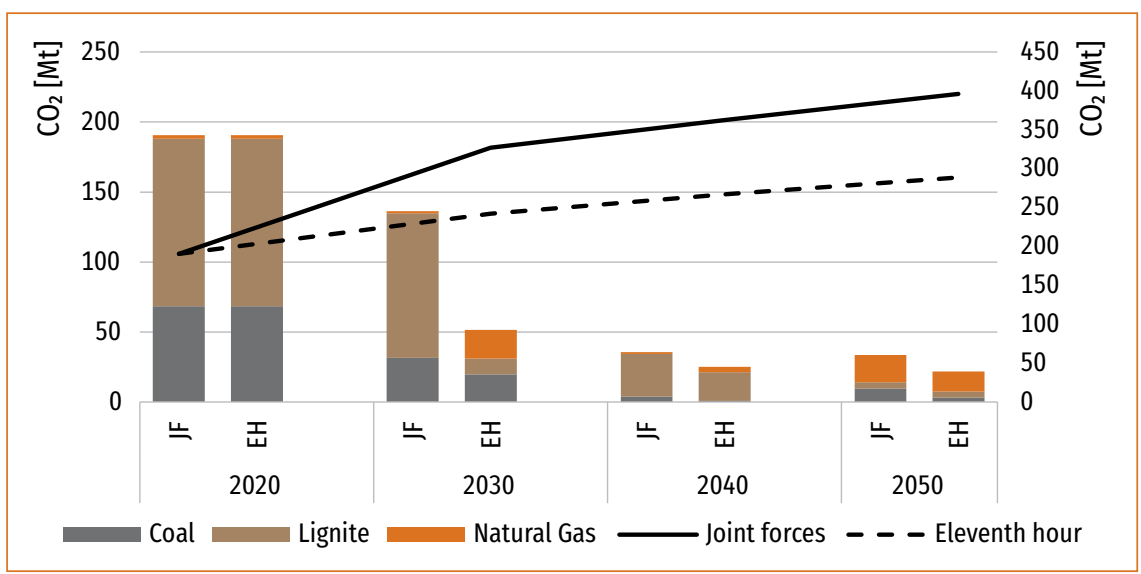

Fig. 4: $\mathrm{CO}_{2}$ emissions by fuel (left axis) and cumulative $\mathrm{CO}_{2}$ emissions (right axis).

Source: Authors' own calculation ate a more comprehensive understanding of possible future developments. In the field of energy and climate research, the presented approach of thresholds and cycles can be utilized to identify a broad variety of nonlinearities, as for example risks of irreversible environmental or climate damages, changes of public attitudes and perspectives, as well as technological leaps. Furthermore, it can shed light on changing market or regulation conditions, that can significantly impact the deployment of energy systems.

With the new methodology presented in this article, we are able to assess impacts of fluctuating parameters, on changing policy attitudes and public perceptions and thresholds or irreversible developments. By linking CIB scenarios, it is possible to describe dynamic storylines. Since (quantitative) energy models usually are used to describe the development of energy systems in 5- or 10-year time steps, the application of such dynamic storylines helps to put storyline and quantitative scenarios in line. The storylines developed based on this rather plain specification show that the pathways to achieve reasonable $\mathrm{CO}_{2}$ reductions do not have to be linear but can be characterized by different kinds of nonlinearities. By laying out the main findings of our approach, we show the need for novel approaches in order to increase our knowledge on possible pathways, which could enhance the effectiveness of policy advice relying on longterm scenarios.

As our example shows, the CIB approach is a very well suited tool for the assessment of plausible future developments. The range of different scenarios carried out by interlinking CIB-scenarios (identified as possible settings for different sub-periods) can be large. While the implementation of this methodology can be challenging due to the high amount of possible scenario configurations, it allows taking into account a broad range of nonlinearities.

\section{References}

Alcamo, Joseph; Henrichs, Thomas (2008): Chapter two towards guidelines

for environmental scenario analysis. In: Developments in Integrated Environmental Assessment 2, pp. 13-35.
Ayres, Robert (2000): On forecasting discontinuities. In: Technological Forecasting and Social Change 65 (1), pp. 81-97.

Azariadis, Costas; Drazen, Allan (1990): Threshold externalities in economic development. In: The Quarterly Journal of Economics 105 (2), pp. 501-526.

Bauer, Nico et al. (2017): Shared socio-economic pathways of the energy sector. Quantifying the narratives. In: Global Environmental Change 42, pp. 316-330. DOI: 10.1016/j.gloenvcha.2016.07.006.

Burt, George (2007): Why are we surprised at surprises? Integrating disruption theory and system analysis with the scenario methodology to help identify disruptions and discontinuities. In: Technological Forecasting and Social Change 74 (6), pp.731-749.

Capros, Pantelis et al. (2016): EU Reference Scenario 2016. Publications Office of the European Union: Luxembourg.

de Bruyn, Sander; van den Bergh, Jeroen; Opschoor, Johannes (1998): Economic growth and emissions. Reconsidering the empirical basis of environmental Kuznets curves. In: Ecological Economics 25 (2), pp. 161-175.

Döll, Petra; Krol, Maarten (2002): Integrated scenarios of regional development in two semi-arid states of North-Eastern Brazil. In: Integrated Assessment 3 (4), pp. 308-320.

EIA - Energy Information Administration (2019): Annual energy outlook 2019. Washington: U. S. Energy Information Administration.

Faber, Malte; Proops, John (1993): Evolution, time, production and the environment. Berlin: Springer-Verlag.

Fagerberg, Jan (2003): Schumpeter and the revival of evolutionary economics. An appraisal of the literature. In: Journal of Evolutionary Economics 13 (2), pp. 125-159.

Grossmann, Iris (2007): Critical and strategic factors for scenario development and discontinuity tracing. In: Futures 39 (7), pp. 878-894.

Grubler, Arnulf; Wilson, Charlie (2013): Energy technology innovation. Learning from historical successes and failures. Cambridge, UK: Cambridge University Press.

IEA - International Energy Agency (2016): World energy outlook. Paris: IEA/OECD.

IEA (2018) World energy outlook. Paris: IEA/OECD.

IPCC - Intergovernmental Panel on Climate Change (2001): Climate change 2001. Mitigation. Cambridge, UK: Cambridge University Press. 
IPCC (2011): IPCC special report on renewable energy sources and climate change mitigation. Cambridge, UK: Cambridge University Press.

IPCC (2018): Global Warming of $1.5^{\circ} \mathrm{C}$. An IPCC Special report on the impacts of global warming of $1.5^{\circ} \mathrm{C}$ above pre-industrial levels and related global greenhouse gas emission pathways, in the context of strengthening the global response to the threat of climate change, sustainable development, and efforts to eradicate poverty. Available online at https://www.ipcc.ch/ sr15/download/\#full, last accessed on 09. 09.2019.

Kemp-Benedict, Eric (2004): From narrative to number. A role for quantitative models in scenario analysis. Available online at http://www.iemss.org/ iemss2004/pdf/scenario/kempfrom.pdf, last accessed on 05.09.2019.

Kosow, Hannah; Gaßner, Robert (2008): Methods of future and scenario analysis. Overview, assessment, and selection criteria. Bonn: Deutsches Institut für Entwicklungspolitik.

Lempert, Robert; Collins, Myles (2007): Managing the risk of uncertain threshold responses. Comparison of robust, optimum, and precautionary approaches. In: Risk Analysis 27 (4), pp. 1009-1026. DOI: 10.1111/j.1539-6924.2007.00940.x.

Mathijs, Erik; Swinnen, Johan (2001): Production organization and efficiency during transition. An empirical analysis of East German agriculture. In: Review of Economics and Statistics 83 (1), pp. 100-107.

Metcalfe, John (1994): Evolutionary economics and technology policy. In: Economic Journal 104 (425), pp. 931-944.

Nelson, Richard; Winter, Sidney (1982): An evolutionary theory of economic change. Cambridge, MA: Belknap Press.

Nelson, Richard; Winter, Sidney (2002): Evolutionary theorizing in economics. In: Journal of Economic Perspectives 16 (2), pp.23-46. DOI: 10.1257/0895330027247.

Patel, Pari; Pavitt, Keith (1997): The technological competencies of the world's largest firms. Complex and path-dependent, but not much variety. In: Research Policy 26 (2), pp. 141-156.

Safarzynska, Karolina; van den Bergh, Jeroen (2010): Evolutionary models in economics. A survey of methods and building blocks. In: Journal of Evolutionary Economics 20 (3), pp. 329-373.

Schumpeter, Joseph (1943): Capitalism, socialism, and democracy. New York: Harper \& Bros

Schweizer, Vanessa; Kriegler, Elmar (2012): Improving environmental change research with systematic techniques for qualitative scenarios. In: Environmental Research Letters 7 (4), pp. 1-14. DOI: 10.1088/1748-9326/7/4/044011.

van Notten, Philip; Sleegers, Am; van Asselt, Marjolein (2005): The future shocks. On discontinuity and scenario development. In: Technological Forecasting and Social Change 72 (2), pp. 175-194.

Veblen, Thorstein (1898): Why is economics not an evolutionary science? In: The Quarterly Journal of Economics 12, pp. 373-397.

Vögele, Stefan; Poganietz, Witold-Roger; Kunz, Paul; Weiss, Annika (2018a): Analyse dynamischer Entwicklungen mittels der Cross-Impact-Balance Methode. Jülich: Forschungszentrum Jülich.

Vögele, Stefan; Rübbelke, Dirk; Mayer, Philip; Kuckshinrichs, Wilhelm (2018b): Germany's "No" to carbon capture and storage. Just a question of lacking acceptance? In: Applied Energy 214, pp. 205-218.

Weimer-Jehle, Wolfgang (2006): Cross-impact balances. A system-theoretical approach to cross-impact analysis. In: Technological Forecasting and Social Change 73 (4) pp. 334-361.

Weimer-Jehle, Wolfgang et al. (2016): Context scenarios and their usage for the construction of socio-technical energy scenarios. In: Energy 111, pp. 956-970.

Winterscheid, Axel (2008): Scenario technique in flood risk management (in German). PhD-thesis. Reports of the Institute for Hydraulic Engineering Vol. 143. Darmstadt: Technical University of Darmstadt (Germany).

Witt, Ulrich (2008): What is specific about evolutionary economics? In: Journal of Evolutionary Economics 18 (5), pp. 547-575. D0I: 10.1007/s00191-008-0107-7.

World Nuclear Association (2019): Country profiles. Available online at http:// www.world-nuclear.org/information-library/country-profiles.aspx, last accessed on 21. 06.2019.

Zhang, Yong-Xiang; Chao, Qing-Chen; Zheng, Qiu-Hong; Huang, Lei (2017): The withdrawal of the U.S. from the Paris Agreement and its impact on global climate change governance. In: Advances in Climate Change Research 8, pp. 213-219. D0I: 10.1016/j.accre.2017.08.005.
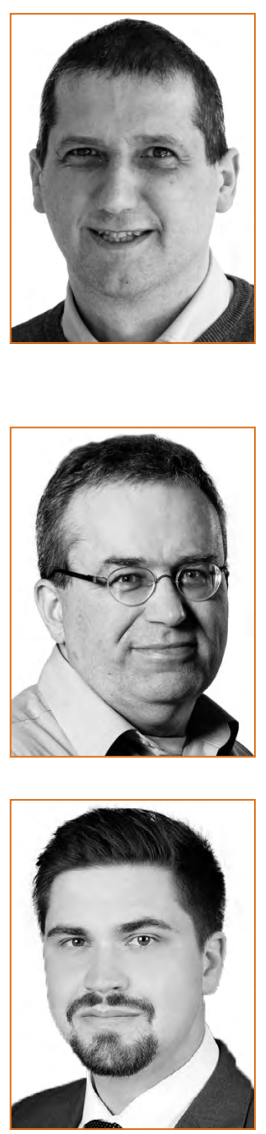

\section{DR.STEFAN VÖGELE}

is employed since 2000 as senior scientist at the Forschungszentrum Jülich, Institute for Energy and Climate Research, Systems Analysis and Technology Evaluation (IEK-STE) with focus on energy economics. He studied economics at the RuprechtKarls-University Heidelberg and received a doctoral degree in economics from Osnabrück University, Germany.

\section{DR. WITOLD-ROGER POGANIETZ}

works at the Institute for Technology Assessment and Systems Analysis (ITAS). His research interests are on socio-technical drivers and impediments of the transformation of energy systems in Europe as well as in countries of the "Global South".

\section{PHILIP MAYER}

is a research associate at the Chair of Economics of TU Bergakademie Freiberg, since 2017. He studied management of renewable energies at Weihenstephan-Triesdorf University of Applied Sciences, Germany and received his masters' degree in energy and resource management at TU Bergakademie Freiberg, Germany. 